\title{
Paisagens Zooliterárias
}

송 


\title{
No TEMPO EM QUE OS ANIMAIS FALAVAM WHEN THE ANIMALS TALKED
}

\author{
Marisa Lajolo* \\ Unicamp/Mackenzie
}

\begin{abstract}
RESUMO
Fábulas constituem um gênero antiquíssimo, já documentado em civilizações pré-cristãs. As raízes do fabulário que chega ao Brasil são greco-latinas, e na palavra "fábula" a etimologia aponta o significado de "falar", ação que, atribuída a animais ou a seres inanimados, é responsável pelo caráter "maravilhoso" do gênero. O texto a ser apresentado discutirá modos da presença de animais em fábulas em circulação no Brasil através da obra de Monteiro Lobato.
\end{abstract}

\section{PALAVRAS - CHAVE}

Fábula, Monteiro Lobato, animais, literatura infantil À Maria Helena de Moura Neves, minha colega de fabulações
em tantos cursos

- Mas será mesmo que os animais desta terra são falantes, ou faz de conta que falam? perguntou Narizinho.

- Falam pelos cotovelos! - respondeu Peninha. Falam para que possa haver fábulas. Vamos andando por este rio acima, a que logo encontraremos algum. ${ }^{1}$

A palavra "fábula" - que em português dá nome a um dos mais singelos e antigos tipos de narrativa - tem uma história interessante. Já existia em latim (fabula, fabulae), onde tem suas raízes no verbo for-fari-fatus e significa "falar". Esse verbo é riquíssimo de significados: sua riqueza semântica talvez se manifeste no amplo leque de expressões que, nascidas dele, permanecem em línguas modernas como o português, em cujo vocabulário suas raízes figuram, por exemplo, em confabular, fabuloso, afável, infância e fado (no sentido de destino).

A palavra "fábula" tem, assim, uma sugestiva etimologia: sua história a enraíza no mundo romano e o tipo de narrativa que ela designa é mais antigo ainda: as Fábulas de Esopo vêm da Grécia e datam do século 6 a C., e as de Fedro (c. 20 a C- 50 d C), do

\footnotetext{
*marisal@uol.com.br

${ }^{1}$ LOBATO. A barca de Gleyre, p. 104.
} 
século 1 da era cristã. Foi nessas coletâneas de histórias que autores mais modernos como La Fontaine (1621-1695) - na França do século 17 - e Bocage (1765-1805) - no Portugal do século 19 - se inspiraram e recolheram as histórias que enfeixaram em livros que ganharam mundo e fornecem as matrizes constantemente retomadas por escritores das mais diferentes tradições e estilos.

Dentre os autores que representam a ponta brasileira dessa genealogia de narradores que remonta à Antiguidade, temos Monteiro Lobato (1882-1948), que em 1921 publica Fábulas de Narizinho. ${ }^{2}$ Não obstante ser obra dos princípios da produção lobatiana, esse livro parece manifestar o profundo senso comercial do escritor que, desde 1918, acumulava a produção de textos (marca distintiva do escritor) com a produção de livros (marca distintiva do editor). O sucesso da publicação de A menina do narizinho arrebitado, obra de 1920 lançada pela Editora Monteiro Lobato \& Cia, talvez recomendasse a inclusão do nome da personagem-título do livro anterior, no título da nova obra que, como o próprio autor diz na abertura do livro, nada mais é do que a recolha e a reescrita de velhas histórias que, bem antes dele, já circulavam.

Com a palavra, Lobato:

As fábulas constituem um alimento espiritual correspondente ao leite da primeira infância. Por meio delas a moral, que não é outra coisa mais que a própria sabedoria da vida acumulada na consciência da humanidade, penetra na alma infante conduzida pela loquacidade inventiva da imaginação.

Essa boa fada mobiliza a natureza, dá fala aos animais, às árvores, às águas e tece com esses elementos pequeninas tragédias donde ressurte a "moralidade", isto é, a lição da vida. O maravilhoso é o açúcar que disfarça o medicamento amargo e torna agradável a sua ingestão.

$\mathrm{O}$ autor nada mais fez senão dar forma às velhas fábulas que Esopo, La Fontaine e outros criaram. Algumas são tomadas de nosso "folk-lore" e todas trazem em mira contribuir para a criação da fábula brasileira, pondo nelas a nossa natureza e os nossos animais sempre que isso é possível. ${ }^{3}$

Ao lado das informações das fontes às quais recorreu - Esopo, La Fontaine e o folclore brasileiro - nessa apresentação que Monteiro lobato faz de seu livro, com uma dose de boa vontade -, podem-se encontrar alguns tópicos bastante interessantes para o papel das fábulas - e da presença, nelas, de animais - na discussão de leitura e literatura. Particularmente do que hoje se denomina Zooliteratura

Já nas primeiras linhas da fala autoral, observa-se o processo de naturalização do gênero que resulta da comparação da fábula com o leite materno. Logo a seguir, Lobato define a moral como sabedoria, tonando-a ahistórica, isto é, é invariável, já que é acumulada na consciência da humanidade. Segundo ele, os valores morais não se alteram nem ao longo do tempo, nem ao longo do espaço, ou seja, valores morais permanecem os mesmos, independentemente da mudança de contexto.

Vale lembrar, a propósito dessa formulação, algumas civilizações antigas nas quais a escravidão de povos era admitida, ou crianças e mulheres não tinham direitos. Esses

\footnotetext{
${ }^{2}$ Cf. Loide Nascimento de Souza, Monteiro Lobato e o processo de re-escritura das fábulas, citado por LAJOLO; CECCANTINI. Monteiro Lobato livro a livro (obra infantil), p. 103-119.

${ }^{3}$ LOBATO. Fábulas de Narizinho, 1921, s. p.
} 
casos apontam o equívoco lobatiano. Mas, lembrar a permanência de fábulas em livros didáticos brasileiros do século 21 mostra que Lobato também tinha razão: certas sabedorias permanecem. Da mesma forma, a imobilidade de certos comportamentos e valores representados pelos mesmos animais que já figuravam em fábulas mais antigas por exemplo, a astúcia da raposa, a ferocidade do lobo ou a operosidade da formiga também parece dar razão a Lobato.

As linhas finais do primeiro parágrafo da transcrição acima revelam-se cheias de palavras cuja etimologia (de novo trazendo à luz raízes latinas) conota linguagem e fala (infante e loquacidade), sublinhando as marcas fortes de oralidade e da destinação infantil que o gênero foi desenvolvendo.

No segundo parágrafo, a identidade das fábulas avança através de metáforas que referem a imaginação como fada.

O autor-editor elenca características que definem literária e discursivamente o gênero, em admirável concisão que nada fica a dever a formulações contemporâneas, quer vindas da área dos estudos literários, quer da área dos estudos do discurso. Resgatando do primeiro parágrafo a menção à imaginação, Monteiro Lobato credita-lhe ao lado do status de ser fantástico (boa fada) o poder de conferir o poder da palavra a seres não humanos: animais, árvores e águas.

É nesse tópico - atribuir poder de fala a seres que dela não dispõem no mundo histórico - que literária e discursivamente repousa a identidade do gênero fábula, originalmente de circulação em verso e, no mundo moderno, indiferentemente em verso ou em prosa.

Monteiro Lobato aponta ainda como traço característico da fábula a explicitação de uma moralidade. Unificando assim os traços que o escritor confere à fábula, podemos defini-la como uma história curta, de que participam personagens não humanas, cujas ações e falas ilustram uma moralidade. São histórias predominantemente povoadas de bichos que falam, como sugerem título e epígrafe deste trabalho.

É exatamente na capacidade de fala que os animais protagonistas da fábula ascendem (?) à categoria de humanos se pensarmos que no Gênesis foi apenas o homem que o Criador dotou de linguagem verbal, comandando: "Ide e daí nome a todas as coisas."

É nessa atribuição do poder de fala a entidades geralmente incapazes dela que se encontra uma possível hipótese para a presença do radical do verbo fari (= falar) na palavra fabula. Outra hipótese para essa etimologia é o fato de fábulas serem, geralmente, contadas, sendo sua circulação de boca a ouvido, desfiadas ao pé do fogo ou em noites de varanda em casas de fazenda, por gerações e gerações, nos quatro cantos do mundo. Ou seja, questões de fala e de oralidade fazem-se presentes no gênero fábula, quer no interior das histórias, quer no seu modo de circulação.

Nos dois últimos parágrafos da apresentação que Monteiro Lobato escreve para seu livro - acima transcrita - encontra-se ainda menção a outras características do gênero. Na imagem do açúcar que recobre o gosto amargo do medicamento pode reconhecer-se o caráter pedagógico das fábulas, o que se confirma pela longa e ainda contemporânea presença delas em livros didáticos, bem como sua milenar reprodução em livros voltados para o público infantil. 
No quarto e último parágrafo confirma-se a dimensão intertextual do gênero - ou, digamos, de sua reescritura - quando Lobato nomeia suas fontes (dar forma a velhas fábulas de Esopo e La Fontaine) citando autores e repertórios culturais aos quais recorreu como matriz narrativa. As linhas finais do parágrafo, ao mencionarem "nosso folclore, nossa natureza e nossos animais", introduzem no livro um aspecto não mais apenas relativo ao gênero, mas também relativo à literatura lobatiana. O escritor explicita seu projeto de nacionalização da cultura brasileira, através da inclusão de animais e cenários brasileiros.

Um tal movimento - ao lado da presença de animais, que, como apontamos acima, por assim dizer, chancela a dimensão universal do gênero dando fiança dessa universalidade - aponta também para sua capacidade de nacionalizar-se e regionalizar-se, numa instigante e produtiva dialética entre permanência e mudança, o mesmo e o outro.

Torna-se interessante, então, daqui para a frente, debruçarmo-nos sobre a questão: como Monteiro Lobato - considerado, geralmente, como irreverente e crítico - lida com a vocação pedagógica, educativa e moralizante do gênero fábula? Em versões posteriores à primeira edição de seu livro de fábulas - que rapidamente perde o possessivo "de Narizinho"-, o escritor introduz uma cena familiar na qual os moradores do sítio, depois de cada fábula, discutem-na sem papas na língua. Mas não é desta irreverência que se vai tratar aqui. Também a história da produção de Fábulas de Narizinho já aponta alguns traços da crítica lobatiana.

Cinco anos antes de publicar o livro (que é de 1921), em carta ao amigo Godofredo Rangel (datada de 8 de setembro de 1916), Monteiro Lobato ancora em uma experiência familiar e doméstica - ouvir/ver a esposa (Dona Purezinha) contar histórias aos filhos - seu interesse inicial pelo gênero fábula. Na época, ele morava em uma fazenda no interior paulista: sua filha mais velha - Marta - tinha 7 anos, e seus caçulas - Edgard e Guilherme - 6 e 4 anos.

Registrando a cena, Monteiro Lobato comenta a reação das crianças às histórias maternas:

Ando com várias idéias. Uma: vestir à nacional as velhas fábulas de Esopo e La Fontaine, tudo em prosa e mexendo nas moralidades. Coisa para criança. Veio-me diante da atenção curiosa com que meus pequenos ouvem as fábulas que Purezinha lhes conta. Guardamnas de memória e vão recontá-las aos amigos - sem, entretanto, prestarem nenhuma atenção á moralidade, como é natural. A moralidade nos fica no subconsciente para ir se revelando mais tarde, à medida que progredimos em compreensão. Ora, um fabulário nosso, com bichos daqui em vez dos exóticos, se for feito com arte e talento dará coisa preciosa. As fábulas em português que conheço, em geral traduções de La Fontaine, são pequenas moitas de amora do mato - espinhentas e impenetráveis. Que é que nossas crianças podem ler? Não vejo nada. Fábulas assim seriam um começo da literatura que nos falta. ${ }^{4}$

A carta é preciosa: sublinha as alterações que Lobato pretende introduzir na reescritura das histórias: nacionalização de personagens e enredos, coloquialização da linguagem e minimização das moralidades.

Os comentários de Monteiro Lobato, inspirados numa cena doméstica por ele testemunhada, reforçam a oralidade tradicional do gênero: Purezinha - como ele

${ }^{4}$ LOBATO. Reinações de Narizinho, p. 104. 
chamava a esposa - conta fábulas aos filhos que as recontam aos amigos. Mas essa oralidade - bastante acentuada ao tempo de Esopo e de Fedro - esvai-se na modernização do gênero que se torna escrito já nas mãos de La Fontaine. A carta de Lobato parece mimetizar resumidamente esse percurso quando ao final menciona a substituição da oralidade pela escrita: "o que é que nossas crianças podem ler?" pergunta (retoricamente) o missivista - futuro escritor e editor -, que arremata obscurecendo bastante o perfil oral do gênero: "fábulas assim seriam um começo da literatura que nos falta".

Vale apontar aqui, ainda que só de passagem, que assim como fala está na raiz etimológica de fábula, letra (= escrita) está na raiz etimológica da palavra literatura. Em 1916 - ano da carta - Monteiro Lobato já tinha muita relação com o mundo dos livros, mas não tantas quantas terá, a partir de 1918, quando se torna proprietário da Revista do Brasil.

É essa transição de um Monteiro Lobato ouvinte ocasional de histórias contadas a seus filhos para o Lobato escritor e editor, que se revela, de forma muito sugestiva, em outra carta, dirigida ao mesmo Godofredo Rangel, quase três anos depois. Nas novas maltraçadas (de 13 de abril de 1919), fábulas voltam à correspondência, que também registra a presença do gênero na tradição brasileira de livros para a infância:

Tive a idéia do livrinho que vai para experiência do público infantil escolar, que em matéria fabulística anda a nenhuma. Há umas fábulas de João Kopke, mas em verso - e diz o Correia que os versos do Kopke são versos do Kopke, isto é, insulsos e de não fácil compreensão por cérebros ainda tenros. Fiz então o que vai. Tomei de La Fontaine o enredo e vesti-o à minha moda, ao sabor do meu capricho, crente como sou de que o capricho é o melhor dos figurinos. A mim me parecem boas e bem ajustadas ao fim - mas a coruja sempre acha lindos os filhotes. Quero de ti duas coisas: juízo sobre a sua adaptabilidade à mente infantil e anotação dos defeitos de forma. $(. . .)^{5}$

A nova carta abre-se já mencionando as Fábulas de João Kopke, ${ }^{6}$ obra face à qual Lobato comporta-se como editor: ele detecta uma carência do mercado (um nicho mercadológico, como hoje se diria), avalia o produto da concorrência, encomenda testagem do novo produto (= o original que envia) - tudo com vista a desalojar os concorrentes. ${ }^{7}$ Os muitos milhares de exemplares vendidos de suas Fábulas atestam a correção e o acerto de sua análise. ${ }^{8}$

\footnotetext{
${ }^{5}$ LOBATO. Reinações de Narizinho, p. 193.

${ }^{6}$ KOPKE. Fábulas. Cf. GALVÃO. Ler, escrever e aprender gramática para a vida prática: uma história do letramento escolar no século XIX.

${ }^{7}$ Em uma interpretação mais marota, pode-se ler essa carta encontrando nela estratagemas editoriais (e mesmo autorais) dos quais a tradição brasileira não é jejuna: em 1870, ao postular novos traços para a literatura brasileira, Machado de Assis desaloja José de Alencar, com a mesma falta de cerimônia com a qual Monteiro Lobato pretende desalojar João Kopke da posição que este ocupava como autor de livros infantil (cf. MACHADO DE ASSIS. Notícia da atual literatura brasileira: Instinto de Nacionalidade).

${ }^{8}$ Em carta de 27 de fevereiro de 1941, Octales Marcondes Ferreira, então Diretor Proprietário da Cia Editora Nacional, informa, a pedido de Monteiro Lobato, as tiragens de sua obra, especificando para Fábulas: dez mil exemplares entre 1918-1925; cinco mil exemplares em 1929, dez mil exemplares em 1934, cinco mil exemplares em 1937 e mais cinco mil exemplares e 1939 o que perfaz um total de trinta e cinco mil exemplares em 14 anos. Cf. Fundo Monteiro Lobato CEDAE- UNICAMP. Correspondência Passiva MLb 3.2.00407 cx 9.
} 
Aponta-se num parêntesis que João Kopke efetivamente faz parte do horizonte no qual Monteiro Lobato tece seus planos editoriais de livros infantis. Ao encomendar a impressão de seu primeiro livro infantil, o modelo fornecido é um livro de Kopke, como registra documento da gráfica encarregada da impressão do livro.

Uma última observação relativamente a essa última carta mostra um Lobato que muda de posição no sistema literário, passando de escritor-editor a leitor - um leitor profundamente envolvido com a força do conteúdo do livro cujo original envia ao amigo.

Ao fazer blague dizendo que "a coruja sempre acha lindos os filhotes", Monteiro Lobato não mais é o escritor-editor de fábulas: é agora um leitor - e um leitor aplicado delas, pois aprende a lição. Para expressar a falta de distanciamento crítico do escritor em relação a sua obra, ele se apropria da moral de uma das fábulas incorporadas a seu livro - A águia e a coruja - cuja bela ilustração consta da capa da primeira edição. A história da águia que devora os filhotes da coruja porque eles lhe haviam sido descritos como belos e ela os achou horrorosos, abre o livro publicado em 1921, Fábulas de Narizinho, que será incessantemente reescrito e republicado, até a edição derradeira, da obra completa - Série infantil - que o escritor organiza para a Editora Brasiliense em 1947.

Ao apropriar-se da moral de uma das fábulas que reúne em seu livro, Monteiro Lobato inverte a tradicional antropomorfização dos animais; opera, ao contrário, uma animalização de sua pessoa, ironia suprema - mas também sabedoria profunda, para quem, em obra posterior - Caçadas de Pedrinho - pela boca de uma capivara -, declara que "não é a toa que os macacos se parecem tanto com os homens. Só dizem bobagens."

\section{A B S T R A C T}

Fable is an ancient genre documented in pre-Christian civilizations. The roots of the fables that arrive in Brazil are Latin and Greek and in the word "fable", the etymology suggests, there is the meaning of "talk", an action that is attributed to animals or to inanimate beings is responsible for the "wonderful" aspect of the genre. The text to be analyzed will discuss the presence of animal fables in circulation in Brazil through the work of Monteiro Lobato.

\section{KEYWORDS}

Fable, Monteiro Lobato, animals, children's literature

${ }^{9}$ LOBATO. Caçadas de Pedrinho, p. 23. 


\section{REFERÊNCIAS}

LOBATO, Monteiro. A barca de Gleyre. São Paulo: Brasiliense. 1956. t. 2.

LAJOLO, M.; CECCANTINI, J. L. (Org.). Monteiro Lobato livro a livro (obra infantil). São Paulo: IMESP/Editora Unesp, 2009.

LOBATO, Monteiro. Reinações de Narizinho. São Paulo: Globo. 2007. v. 2.

KOPKE, João. Fábulas. São Paulo: Teixeira \& Irmão, 1891.

GALVÃO, Ana Maria de Oliveira. Ler, escrever e aprender gramática para a vida prática: uma história do letramento escolar no século XIX. Lingua Escrita, CEALE, n. 1, jan.-abr. 2007. Disponível em: <>. Acesso em: 3 jun. 2011.

MACHADO DE ASSIS, Joaquim Maria. Notícia da atual literatura brasileira: Instinto de nacionalidade. In: Obra completa. Rio de Janeiro: Nova Aguilar. 2008. v. III. p. 1203-1206

LOBATO, Monteiro. Caçadas de Pedrinho. São Paulo: Globo 2009. 